\title{
Genetic diversity of expressed Plasmodium falciparum var genes from Tanzanian children with severe malaria
}

\author{
Joseph Mugasa ${ }^{1,2}$, Weihong Qi ${ }^{2,4}$, Sebastian Rusch ${ }^{2,3}$, Matthias Rottmann ${ }^{2,3}$ and Hans-Peter Beck ${ }^{2,3^{*}}$
}

\begin{abstract}
Background: Severe malaria has been attributed to the expression of a restricted subset of the var multi-gene family, which encodes for Plasmodium falciparum erythrocyte membrane protein 1 (PfEMP1). PfEMP1 mediates cytoadherence and sequestration of infected erythrocytes into the post-capillary venules of vital organs such as the brain, lung or placenta. var genes are highly diverse and can be classified in three major groups (ups $A, B$ and C) and two intermediate groups (B/A and B/C) based on the genomic location, gene orientation and upstream sequences. The genetic diversity of expressed var genes in relation to severity of disease in Tanzanian children was analysed.
\end{abstract}

Methods: Children with defined severe (SM) and asymptomatic malaria (AM) were recruited. Full-length var mRNA was isolated and reversed transcribed into var CDNA. Subsequently, the DBL and N-terminal domains, and up-stream sequences were PCR amplified, cloned and sequenced. Sequences derived from SM and AM isolates were compared and analysed.

Results: The analysis confirmed that the var family is highly diverse in natural Plasmodium falciparum populations. Sequence diversity of amplified var DBL-1a and upstream regions showed minimal overlap among isolates, implying that the var gene repertoire is vast and most probably indefinite in endemic areas. var DBL-1 a sequences from AM isolates were more diverse with more singletons found $(p<0.05)$ than those from SM infections. Furthermore, few var DBL-1 a sequences from SM patients were rare and restricted suggesting that certain PfEMP1 variants might induce severe disease.

Conclusions: The genetic sequence diversity of var genes of $P$. falciparum isolates from Tanzanian children is large and its relationship to disease severity has been studied. Observed differences suggest that different var genes might have fundamentally different roles in the host-parasite interaction. Further research is required to examine clear disease-associations of var gene subsets in different geographical settings. The importance of very strict clinical definitions and appropriate large control groups needs to be emphasized for future studies on disease associations of PfEMP1.

Keywords: Plasmodium falciparum, Severe malaria, var genes, PfEMP1, Expression, Diversity

\footnotetext{
* Correspondence: hans-peter.beck@unibas.ch

${ }^{2}$ Swiss Tropical and Public Health Institute, Socinstrasse 57 Postfach, Basel 4002, Switzerland

${ }^{3}$ University of Basel, Switzerland

Full list of author information is available at the end of the article
}

\section{Biomed Central}

(c) 2012 Mugasa et al.; licensee BioMed Central Ltd. This is an Open Access article distributed under the terms of the Creative Commons Attribution License (http://creativecommons.org/licenses/by/2.0), which permits unrestricted use, distribution, and reproduction in any medium, provided the original work is properly cited. 


\section{Background}

Despite all efforts to curb Plasmodium falciparum malaria infections it still is an important cause of morbidity and mortality in many developing countries, with an estimated 700,000 deaths annually [1]. The burden of disease is highest in children below five years of age where much of the mortality is attributable to severe malaria. Except for RTS,S, which is currently in clinical phase 3 trial, no vaccine is available to date, but vaccine development is encouraged by the fact that children living in endemic areas attain conditional immunity to severe malaria after a relatively few number of episodes during childhood [2]. Genetic diversity of different parasites and antigenic variation of surface antigens pose an obstacle for vaccine development.

Severe malaria, the most life threatening form of the disease is believed to be mediated by cytoadhesion of $P$. falciparum-infected erythrocytes to a variety of receptors on the endothelial lining of the host's blood capillaries. This post-capillary sequestration severely affects vital organs such as the brain, kidneys, lungs or placenta [3]. Cytoadherence is conferred by $P$. falciparum derived proteins on the surface of infected erythrocytes that play a key role as both virulence factors and as targets of naturally acquired immunity $[4,5]$. Of these, the major contributor to pathology of $P$. falciparum is the $P$. falciparum erythrocyte membrane protein 1 (PfEMP1). PfEMP1 is a large protein of approx. $200-400 \mathrm{kDa}$, it is a highly polymorphic antigen which is encoded by a family of 60 var genes per haploid genome [6]. Var genes present with a two-exon structure encoding a semiconserved C-terminus that contains a predicted transmembrane region, and a highly polymorphic extracellular $\mathrm{N}$-terminus. This part has a modular structure containing various numbers of Duffy-binding-like (DBL) domains and cysteine-rich domains that have been shown to be involved in sequestration of the infected erthrocytes [7-9]. The most $\mathrm{N}$-terminal sequence including the DBL $\alpha$ domain is the most conserved domain within the var gene domains also conferring cytoadherence $[10,11]$. A range of host receptors have been shown to interact with PfEMP1 thus determining the binding to various tissues $[10,12,13]$. Rosetting and sequestration conferred by expression of different PfEMP1 molecules has been implicated in severe disease [14].

var genes have been classified into three major groups (A, B and $\mathrm{C}$ ) and two intermediate groups (B/A and $B / C$ ) based on the presence of one of the $5^{\prime}$ upstream sequences (upsA, B or C), and the position and orientation of the gene within a genomic context $[15,16]$. It has been speculated that severe malaria is determined by the expression of a restricted and antigenically semi-conserved subset of PfEMP1 $[17,18]$. The best understood host-parasite interaction concerning
PfEMP1 is pregnancy-associated malaria (PAM) in which PfEMP1 molecules binding to CSA are involved [19]. var genes have further been sub-classified by the distribution of cysteines throughout the head structures and positions of limited variation (PoLV) [20].

Few studies have investigated the expression of var genes in field isolates representing different forms of severe malaria [21-27]. These studies suggested that the transcription patterns of var genes vary between different malaria manifestations. Differences in epidemiology, severe disease classification, and var classification have also made comparison between studies difficult. Using quantitative real time reverse transcription PCR (qRTPCR), we have previously shown that group A and B var transcripts were up-regulated in children from Tanzania with severe malaria as opposed to asymptomatic infections [25]. Although qRT-PCR is a standard method for detection and quantification of gene expression levels [28], without subsequent sequencing this technique is not informative to study diversity of genes. Given the importance of immunity against PfEMP1 and its possible association with protection against malaria, it is essential to gain amore detailed understanding of diversity of these molecules at sequence level. Only this allows the determination of how such diversity influences the development of protective immunity. In this study, the genetic diversity of expressed PfEMP1 molecules in parasite populations directly isolated from children with severe malaria was examined.

\section{Methods}

\section{Sample collection}

Samples used in this study were collected in a severe malaria (SM) case control study that has been described in detail previously [25]. Briefly, children aged $<59$ months admitted with severe malaria according to WHO guidelines [29] at Saint Francis Referral Hospital (StFRH), Ifakara, Tanzania were recruited into the study after informed consent was obtained from children's parents or guardians. Exclusion criteria were: confirmed coinfections, malnutrition (mid-upper arm circumference [MUAC] of $\leq 12 \mathrm{~cm}$ ), haemoglobin $\leq 5 \mathrm{~g} / \mathrm{dL}$, lactate $\geq 5 \mathrm{mmol} / \mathrm{L}$, glucose $\leq 2.2 \mathrm{mmol} / \mathrm{L}$, or anti-malarial treatment during the last 14 days. A total of 52 patients with SM were recruited. From eight patients meeting the inclusion criteria, cDNA could be obtained and these were grouped as cerebral malaria cases according to WHO guidelines [29] and the modified blantyre coma score $\leq 3$ [30]. Controls were children from nearby villages with asymptomatic malaria (AM) defined as presence of P. falciparum, axillary temperature of $\leq 37.5^{\circ} \mathrm{C}$ and no other symptoms. Children aged $<59$ months were screened for $P$. falciparum infection by using a rapid diagnostic test (RDT), (Paracheck ${ }^{\circledR}$ Pf, Orchid Biomedical 
Systems, Goa, India). Participating children who were found positive by RDT were subsequently confirmed microscopically by Giemsa-stained thick and thin blood film at IHI laboratory. A total of 19 children were initially recruited into the control group, of which only seven could be confirmed $P$. falciparum positive by microscopy. Ethical clearance for this study was obtained from the Ifakara Health Institute and the Medical Research coordinating committee of the National Institute for Medical Research in Tanzania.

From all participating children, one to two $\mathrm{ml}$ of venous blood was drawn into an EDTA tube (Vacutainer, Becton Dickinson, Rutherford, NJ, USA). Between $50-100 \mu \mathrm{L}$ of whole blood was immediately mixed with 2 volumes of $6 \mathrm{~m}$ guanidine $\mathrm{HCl}, 50 \mathrm{mMTris} \mathrm{pH} 8.0,20 \mathrm{mM}$ EDTA and kept at $-20^{\circ} \mathrm{C}$ for gDNA isolation. The remaining erythrocytes (RBC) were separated from serum by centrifugation and washed with $40 \mathrm{ml}$ phosphate buffered saline, 5 volumes TRIzol reagent (Invitrogen) were added to the $\mathrm{RBC}$ pellet before preservation at $-70^{\circ} \mathrm{C}$ until later use.

\section{DNA extraction and genotyping}

Genomic DNA was extracted from frozen blood in guanidine $\mathrm{HCl}$ using QiaAmp blood kit (Qiagen) following the manufacturer's instructions. The minimum number of genotypes per isolate was determined by $\mathrm{msp} 2$ PCR amplification and subsequent Genescan analysis as described by Falk et al. [31]. Briefly, $1 \mu \mathrm{L}$ of purified genomic DNA was used in a $20 \mu \mathrm{L}$ primary PCR reaction, followed by a nested PCR reaction using fluorochrome-labelled primers for both msp 2 allelic families. Capillary electrophoresis was used to determine the number of infecting strains per isolate.

Isolation of full-length var transcripts and RT- PCR Total RNA was extracted by using TRIzol reagent (Invitrogen) twice as recommended by the manufacturer to decrease DNA contamination. Between TRIzol purifications RNA was treated with $3 \mathrm{U}$ of RQ1 RNasefree DNase (Promega). Full-length var mRNA was isolated by using magnetic beads tagged with an oligonucleotide complementary to the acidic terminal sequence (ATS) as previously described [23] with modifications. Briefly, RNA was dissolved in $5 \mathrm{mM}$ Tris, $0.5 \mathrm{mM}$ EDTA, and mixed with binding buffer $(0.5 \mathrm{M} \mathrm{LiCl}, 1 \mathrm{mM}$ EDTA, 10mM Tris, pH 7.5), 15 mM DTT, 40 U RNaseOUT (Invitrogen) and $1 \mathrm{pmol}$ of biotinylated oligonucleotide complementary to the conserved sequence in the ATS domain (Biotin-5'-GGTTC(A/T)A(A/G)TAC(C/T)ACTTC (A/T)AT(C/T)CCTGGT(A/G)CATATATATCATTAATATCCAATTCTTCATA(C/T)TCACTTC(T/G)GA $\left.(\mathrm{A} / \mathrm{T} / \mathrm{G}) \mathrm{GA}-3^{\prime}\right)$. This mixture was incubated $65^{\circ} \mathrm{C}$ for 30 minutes and afterwards kept at $4^{\circ} \mathrm{C}$. Meanwhile $150 \mathrm{mg}$ of Dyna beads m-280 streptavidin (Dynal Biotech, ASA, Oslo, Norway) was washed as suggested by the manufacturer and resuspended in $0.5 \mathrm{M} \mathrm{LiCl}$ and added to the oligonucleotide-RNA hybrids. The mixture was uniformly mixed by rotating for $30 \mathrm{~min}$ at $37^{\circ} \mathrm{C}$. The biotinylated beads-ATS-mRNA complex was washed three times with washing buffer (10 mM Tris, $1 \mathrm{mM}$ EDTA, $0.15 \mathrm{mM}$ $\mathrm{NaCl}, \mathrm{pH}$ 7.5) and once with $10 \mathrm{mM}$ Tris. Reverse transcription (RT) into single stranded cDNA was performed on captured mRNA, primed by random hexamere oligonucleotides in the concentration of $300 \mathrm{ng}$ (Invitrogen) using Sensiscript reverse transcriptase (Qiagen) following the manufacturer's protocol in a final volume of $20 \mu \mathrm{L}$. A second RNA aliquot was treated equally but reverse transcriptase was omitted in the RT-step. This sample served as a control for proving the absence of gDNA. After RT, cDNA was treated with RNaseA (Promega) and $1 \mu \mathrm{L}$ was used for subsequent PCR analyses.

\section{Amplification of var sequences}

The DBL- $1 \alpha$ domain of var genes was PCR amplified from $1 \mu \mathrm{L}$ cDNA using Advantage cDNA polymerase mix (CLONTECH) and the primer sets shown in Table 1.

Table 1 Oligonucleotide primers used for amplification of different fragments of var genes

\begin{tabular}{|c|c|c|c|c|c|}
\hline var Gene region & Size of amplified product & $\mathrm{T}_{\text {anneal }}$ & Name of primer & Primer sequence & Source \\
\hline \multirow[t]{2}{*}{ DBL1a } & $\sim 500$ & 54 & DBLa-5' & 5'-GCACGAAGTTITGCAGATAT(A/T)GG-3'3'- & [23] \\
\hline & & & DBLa-3' & AA(A/G)TCTTC(T/G)GCCCATTCCTCGAACCA-5' & \\
\hline \multirow[t]{3}{*}{ DBL1a-CIDR } & $1.5 \mathrm{~kb}$ & 52 & DBLa-5' & 5'-GCACGAAGTTTTGCAGATAT(A/T)GG-3' & [23] \\
\hline & & & CIDR1.1-3' & 3'-T(C/G/T)TAGTAATTTATC(A/C/T)ATTGT-5' & \\
\hline & & & CIDR1.2-3' & 3'-T(C/G/T)TAATAAGAATTCGATTGC-5' & \\
\hline \multirow[t]{2}{*}{ upsA 5'UTR- DBL1a } & $1.2 \mathrm{~kb}$ & 54 & upsA-5' & 5'-ATTA(C/T)ATTTGTTGTAGGTGA-3' & \\
\hline & & & DBLa-3' & 3'-AA(A/G)TCTTC(T/G)GCCCATTCCTCGAACCA-5' & \\
\hline \multirow[t]{2}{*}{ upsB 5'UTR- DBL1a } & $1.3 \mathrm{~kb}$ & 52 & 17DBLa-5' & 5'-ATGTAATTGTTGTIIIIIIIIIGTTAGAATATITAAA-3' & \\
\hline & & & DBLa-3' & 3'-AA(A/G)TCTTC(T/G)GCCCATTCCTCGAACCA-5' & \\
\hline \multirow[t]{2}{*}{ psC 5'UTR- DBL1a } & $1.3 \mathrm{~kb}$ & 54 & $5 B 1-5^{\prime}$ & 5'-CACATATARTACGACTAAGAAACA-3' & [15] \\
\hline & & & DBLa-3' & 3'-AA(A/G)TCTTC(T/G)GCCCATTCCTCGAACCA-5' & [23] \\
\hline
\end{tabular}


PCR was performed in $25 \mu \mathrm{L} 1.5 \mathrm{mM} \mathrm{MgCl} 2,200 \mu \mathrm{M}$ dNTP mix, $1 \mu \mathrm{M}$ each primer. The cycling conditions were 30 cycles of $94^{\circ} \mathrm{C}$ for $30 \mathrm{~s}, 1 \mathrm{~min}$ at the annealing temperature specified in (Table 1) and for $70 \mathrm{~s}$ at $68^{\circ} \mathrm{C}$. This generated a PCR product of about $\sim 400-500 \mathrm{bp}$ in length.

Three different PCRs were carried out on cDNA to determine the genetic diversity in the upstream sequences using three degenerate forward primers based on sequence alignments of 3D7 var genes (Table 1). These primers amplify homology blocks in the upstream sequences with following sizes: 200 bp for upsA, $400 \mathrm{bp}$ for upsB, and $440 \mathrm{bp}$ for upsC. The reverse primer was chosen from the homology block $\mathrm{H}$ of the first DBL-1 $\alpha$ domain [32]. Primers were tested on genomic DNA from the 3D7 isolate. Amplification of DBL $\alpha$-CIDR $\beta$ fragments was carried out using primers shown in Table 1 . Controls without reverse transcriptase were amplified in parallel for each reaction, and if a PCR product was obtained the $\mathrm{RT}(+)$ sample was discarded and excluded from the analysis.

\section{Cloning and sequencing}

An aliquot of $5 \mu \mathrm{L}$ of each PCR product was visualized in a $1 \%$ agarose gel, the remaining PCR product was purified using the NucleoSpin ${ }^{\circledR}$ Extract II kit (Macherey \& Nagel). The eluted DBL- $1 \alpha$ fragments were cloned into the pGEM-T vector (Promega) according to the manufacturer's instructions and transfected into E.coli SURE cells (Stratagene). 5' upstream regions and DBL- $1 \alpha-C I D R 1$ products were cloned into the $\mathrm{pCR}^{\circledR} 4$-TOPO vector (Invitrogen) and transformed into E.coli TOP10 cells. This vector was more suitable for large fragments $(>1 \mathrm{~kb})$ and for PCR products with low concentration $(<5 \mathrm{ng} / \mu \mathrm{L})$. From each cloning reaction an average of 50 colonies found positive by PCR screening were further processed for sequencing using the Perfectprep ${ }^{\circledR}$ Plasmid 96 Vac Direct bind kit (Eppendorf). The size of each insert was checked from purified plasmids using restriction enzymes NotI and NcoI (New England BioLab) for pGEMT plasmids. EcoRI digests (New England BioLab) were used for TOPO plasmids. Sequencing was carried out using the T7 and SP6 primers for pGEM-T vector, whereas M13 forward and reverse primers were used for the $\mathrm{pCR}^{\circledR} 4$ TOPO using a 96 capillary automated sequencing systems 3700 (Applied Biosystems). A multiple-sequence alignment of sequences derived from the same clinical isolate was carried out to allow the exclusion of PCR derived mutations. Two sequences were considered to be identical when $\geq 96 \%$ amino acid sequence identity was detected.

\section{Sequence analysis}

DNA sequences were assembled and analyzed using ContigExpress in the Vector NTI Advance ${ }^{\mathrm{TM}} 10$ software (Invitrogen) and BLAST from the NCBI webpage
(http://www.ncbi.nlm.nih.gov/BLAST/). BLAST analysis against the 3D7 genome database was performed using the PlasmoDB interface (https://www.pasmoDB.org [33]). DNA sequences were translated using RevTrans1.4 [34]. Amino acids were aligned with either CLUSTALW 1.8 or MUSCLE [35] using default parameters and edited with Bioedit version 7.09 with minor manual adjustment where necessary. Sequences were further categorized into sequence types (STs) by BLASTCUT analysis [36] by which sequences sharing $\geq 96 \%$ sequence identity were assigned the same ST.

\section{Phylogenetic analysis}

Phylogenetic analyses were conducted on multiple sequence alignments of the 3 most dominant sequences from each isolates. Because var genes are subject to intragenic recombination [37], synonymous substitutions are likely to be saturated and DNA sequence analysis would be quite noisy in constructing phylogenetic trees [38]. Therefore, we used protein sequences rather than nucleotide sequences. Two methods were employed in constructing the phylogenic trees. Neighbour-Joining (NJ) trees were constructed by using MEGA 4.0 [39]. The reliability of internal branches for NJ was assessed with 1,000 bootstrap pseudo-replicates using 'pairwise deletion option' of amino acid sequences with p-distance. SplitsTree4 version 4.7 was used to construct the phylogenetic network [40] using the Neighbour-Net distances transformation and equal angle splits transformation.

\section{Results}

\section{Sample collection and clinical data}

A total of 15 children were used in the analysis of the present study of which 8 were in the SM group with cerebral manifestation, Blantyre score $\leq 3$ and 7 children with asymptomatic $P$. falciparum malaria were in the control group. Clinical and epidemiological assessments of all subjects are presented in Table 2. There was a significant difference in age between AM cases (median 52, range 24-59) and SM cases (median 28.5, range 14-40, $p=0.02$, Kruskal-Wallis test). There was also a highly significant differences in parasitaemia between both clinical categories ( $p=0.0012$, Kruskal-Wallis test).

\section{Multiplicity of infection}

$m s p 2$ genotyping indicated that $87.5 \%$ (7/8 SM isolates) had multiple $P$. falciparum clone infections (2-4clones) with an average of 2.6 infecting clones. All isolates from AM children had multiple infections (2 or 3 ) with an average of 2.4 infecting clones (Table 3 ).

\section{DBL-1a sequence types}

A total of 615 var DBL-1 $\alpha$ clones ( 400-500 bp) were successfully sequenced. Of these, 305 sequences were 
Table 2 Clinical and epidemiological assessment of isolates from severe and asymptomatic malaria

\begin{tabular}{|c|c|c|c|c|c|c|c|c|c|c|}
\hline Isolate & Sex & $\begin{array}{l}\text { Age } \\
\text { (months) }\end{array}$ & $\begin{array}{l}\text { Days between } \\
\text { symptoms and } \\
\text { treatment }\end{array}$ & $\begin{array}{l}\text { Parasitemia } \\
\text { (parasites/200 } \\
\text { leukocytes) }\end{array}$ & $\begin{array}{l}\text { Temperature } \\
\left({ }^{\circ} \mathrm{C}\right)\end{array}$ & $\begin{array}{l}\text { MUAC } \\
(\mathrm{cm})\end{array}$ & PCV\% & $\begin{array}{l}\text { Lactate } \\
\mathrm{mmol} / \mathrm{L}\end{array}$ & $\begin{array}{l}\text { Glucose } \\
\mathrm{mmol} / \mathrm{L}\end{array}$ & $\begin{array}{l}\text { Blantyre } \\
\text { score }\end{array}$ \\
\hline \multicolumn{11}{|l|}{ Severe } \\
\hline ISM2 & M & 40 & 3 & 3120 & 38.6 & 17 & 27 & 2.5 & 2.3 & 2 \\
\hline ISM3 & M & 36 & 2 & 2574 & 39.7 & 17 & 16 & 2.4 & 5.9 & 3 \\
\hline ISM11 & M & 33 & 2 & 7344 & 37.0 & 17 & 30 & 4.5 & 3.7 & 3 \\
\hline ISM16 & M & 16 & 3 & 2484 & 38.6 & 14 & 26 & 2.1 & 2.7 & 3 \\
\hline IMS33 & $\mathrm{F}$ & 24 & 3 & 1316 & 37.4 & 16 & 22 & 3.1 & 3.0 & 2 \\
\hline ISM48 & M & 36 & 2 & 4713 & 38.9 & 17 & 31 & 3.0 & 5.0 & 3 \\
\hline ISM49 & M & 14 & 4 & 1907 & 39.9 & 16 & 23 & 1.8 & 6.6 & 3 \\
\hline ISM51 & $\mathrm{F}$ & 16 & 4 & 9999 & 40.0 & 16 & 21 & 5.0 & 8.4 & 2 \\
\hline \multicolumn{11}{|c|}{ Asymptomatic } \\
\hline IAM5 & M & 24 & NA & 830 & 36.7 & ND & 20 & 3.4 & 5.8 & NA \\
\hline IAM7 & $\mathrm{F}$ & 33 & NA & 704 & 36.6 & ND & 14 & 3.3 & 3.9 & NA \\
\hline IAM10 & M & 59 & NA & 70 & 37.5 & ND & 22 & 2.4 & 4.2 & NA \\
\hline IAM11 & $\mathrm{F}$ & 56 & NA & 68 & 36.7 & ND & 23 & 4.6 & 4.4 & NA \\
\hline IAM12 & $\mathrm{F}$ & 47 & NA & 690 & 36.4 & $N D$ & 26 & 4.5 & 8.0 & NA \\
\hline IAM17 & M & 59 & NA & 360 & 37.3 & ND & 28 & 2.5 & 4.9 & NA \\
\hline IAM18 & $\mathrm{F}$ & 52 & NA & 360 & 37.3 & ND & 18 & 3.1 & 4.3 & NA \\
\hline
\end{tabular}

NA Not applicable, ND Not determined.

originating from AM children (Table 3) and were assembled into 131 sequence types (STs) i.e. distinct DBL- $1 \alpha$ sequences. The remaining 310 sequences from SM children were assembled into 127 sequence types. AM patient samples had more singletons (sequences occurring only once) than SM isolates $(\mathrm{p}<0.05)$.

Assembled sequence types showed an extreme diversity in sequence reflecting the high recombination and mutation rates in the DBL- $1 \alpha$ domain. Multiple-sequence alignment of the DBL- $1 \alpha$ sequences showed conserved islands of homology. The dominant sequence from each isolate was blasted against the 3D7 genome. The blasted sequence was assigned the name of the identified 3D7 gene with the high scoring segment pair (Table 3). PCR amplification and cloning efficiency of the var up-stream regions (ups A, upsB, upsC and DBL $1 \alpha-C I D R$ ) were very low and few sequences could be generated. These sequences were, therefore, excluded from the analysis.

\section{Distribution of DBL-1a expressed sequence tags}

The number of distinct transcribed DBL-1 $\alpha$ var gene sequences detected per isolate varied from 8 to 25 (Table 3). All isolates showed a predominant sequence as well as minor transcripts and unique sequence types. The homologous group A transcript to PFD0020c in 3D7 was a predominant transcript in ISM 16 and was among the top three frequent sequences in SM isolates. However, the transcript homologous to PF08_0141 in 3D7 was the predominant transcript in $2 / 7 \mathrm{SM}$ isolates (Table 3 ). In cluster analyses some of the DBL- $1 \alpha$ sequences were found to be shared among isolates (i.e overlapping). A number of transcripts were found in both groups (SM \& AM) and others were specifically found either in SM or in AM isolates. Some sequences were unique to a particular isolate and were not found in other isolates. The distributions of the STs in our 15 isolates are shown in Figure 1. There was no significant difference in the number of distinct DBL- $1 \alpha$ sequences per isolate detected in both clinical groups AM: median 20, range 8-25, SM: median 17.5 , range $12-23,(P=0.72$, Kruskall-Wallis test).

\section{Distribution of DBL-1a expressed sequences tags in clinical isolates}

All sequences generated were classified into six DBL- $1 \alpha$ sequence tag groups by using text string software in MS Excel and Perl which was kindly provided by Dr P Bull (KEMRI, Kilifi, Kenya). This classification of DBL- $1 \alpha$ sequence tags was previously explained in detail by Bull et al. [20]. In summary, it is based on counting the number of cysteine-residues within the tagged region, and in a set of sequence motifs at four positions of limited variability (PoLV 1-4). Figure 2 shows the distribution of PoLV/cys groups in clinical isolates. Analysis of DBL $\alpha$ sequences generated in the present study corresponded well with the cysteine/PoLV grouping. Figure 3 shows the proportional distribution of PoLV motifs between the clinical isolates. Sequence 'signature tags' and the dominant sequence group from each isolate are shown 
Table 3 Summary of analysed sequences of different transcribed var DBL1a sequences

\begin{tabular}{|c|c|c|c|c|c|c|c|}
\hline Isolates & $\begin{array}{l}\text { RT-PCR, cloned in } \\
\text { pGEMT Vector, PCR } \\
\text { screened } 96 \text { clones } \\
\text { picked for sequencing }\end{array}$ & $\begin{array}{l}\text { Sequences } \\
\text { generated } \\
\text { per isolate }\end{array}$ & $\begin{array}{l}\text { Number of } \\
\text { distinct DBLa } \\
\text { var per isolate }\end{array}$ & $\begin{array}{l}\text { Predominant } \\
\text { gene blasted } \\
\text { vs 3D7 }\end{array}$ & $\begin{array}{l}\text { Group } \\
\text { homology } \\
\text { to 3D7 }\end{array}$ & $\begin{array}{l}\text { Bulls' signature } \\
\text { and group }\end{array}$ & $\mathrm{MOI}$ \\
\hline \multicolumn{8}{|l|}{ Severe } \\
\hline ISM 2 & 48 & 42 & 23 & PF08_0141 & A & LFLG-IREY-KAIT-2-LTNL & 2 \\
\hline ISM 3 & 48 & 41 & 22 & PFF0010w & $\mathrm{B} / \mathrm{A}$ & LYLD-FREY-KAIT-2-PTNL & 3 \\
\hline ISM 11 & 60 & 50 & 20 & PFD1005c & $B / C$ & LFIG-LRED-KALT-4-PTYF & 2 \\
\hline ISM 16 & 48 & 36 & 18 & PFD0020c & A & MFKR-LRED-RAIT-2-PTNL & 1 \\
\hline ISM 33 & 60 & 50 & 15 & PFF0010w & A & LFLG-VREY-KAIT-2-LTNL & 3 \\
\hline ISM 48 & 48 & 47 & 12 & PF08_0141 & A & MFLG-IREY-KALT-2-PTNL & 3 \\
\hline ISM 49 & 48 & 44 & 17 & PFL1830c & B & LYLG-LRED-KAIT-4-PTYF & 3 \\
\hline \multicolumn{8}{|c|}{ Asymptomatic } \\
\hline IAM 5 & 48 & 46 & 25 & PF08_0141 & A & MFLG-IREY-KALT-2-PTNL & 3 \\
\hline IAM 7 & 48 & 45 & 8 & PFL 1830c & B & LYLG-LRED-KALT-4-PTYF & 2 \\
\hline IAM 10 & 48 & 38 & 23 & PFD0615c & C & LFIG-LRED-EAIT-4-PTNF & 3 \\
\hline IAM 11 & 48 & 43 & 15 & PFL2665C & B & LYRG-LRED-NAII-3-LTNF & 3 \\
\hline IAM 12 & 48 & 45 & 20 & PFL1955W & $B / C$ & LYLG-LRED-KAIT-4-PTYF & 2 \\
\hline IAM 17 & 48 & 46 & 24 & PFA0005W & B & LYLG-LRED-EAIT-4-PTYF & 2 \\
\hline \multirow[t]{2}{*}{ IAM 18} & 48 & 42 & 16 & PFA0005w & B & LYLG-LRED-KAIT-4-PTYF & 2 \\
\hline & Total & 615 & & & & & \\
\hline
\end{tabular}

in Table 3. A significant association of cys2 sequence tags (groups 1-3) with $\mathrm{SM}$ isolates $(\mathrm{p}<0.0001, \mathrm{CMH}$ test), with an odds ratio of $2.5(95 \% \mathrm{CI}=1.78-3.4)$ was observed. These findings support previous reports that DBL- $1 \alpha$ sequences associated with severe disease have a reduced number of cysteines [21-23]. A two-sample test of proportion showed that expressed PoLV motifs were associated with a particular disease phenotype $(\mathrm{p}<0.0001)$. These PoLV motifs were found strongly associated with severe malaria: in PoLV1 (LDLY and MFKR), in PoLV2 (FREY and LREV), in PoLV3 (NAIT and RAIT), and in PoLV4 (LTNL and PTNL).

\section{Cumulative diversity of DBL-1a sequences in clinical} isolates

To estimate the size of the var gene repertoire in the parasite population under study, the rate at which distinct DBL- $1 \alpha$ sequences changed was simulated with increasing sample size. This simulation was performed separately for AM and SM, as well as the combined data (AM \& SM). The empirical plots were fitted by a linear function. The curves did not plateau with the DBL- $1 \alpha$ sequences generated from the Ifakara area (Figure 4). The repertoire of expressed var genes was unlimited. Thus, var gene diversity in this local population seems

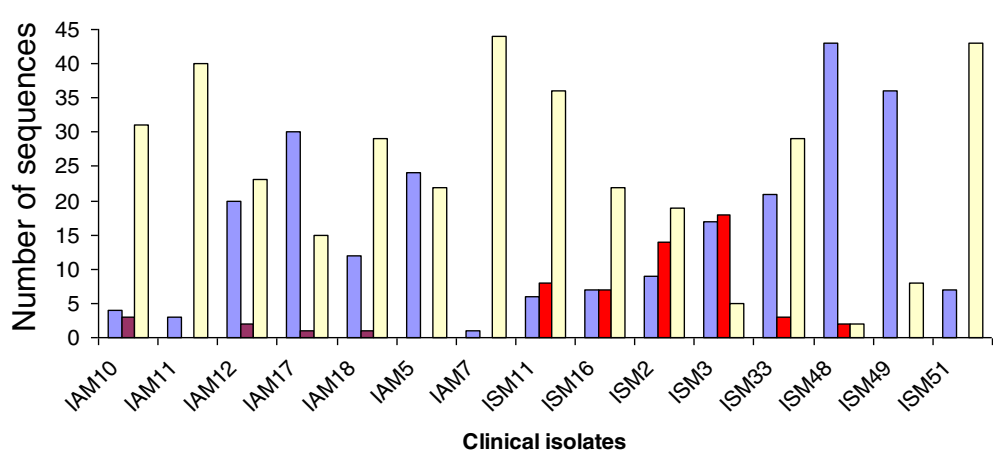

Figure 1 Distribution of unique sequence types (STs) of DBL1a in clinical isolates. Blue columns represent STs found in multiple samples from both AM and SM groups. Red columns represent STs found in multiple samples within the SM group. Pink columns represent STs found in multiple samples within the AM group. Yellow columns represent STs specific to each individual isolate. 


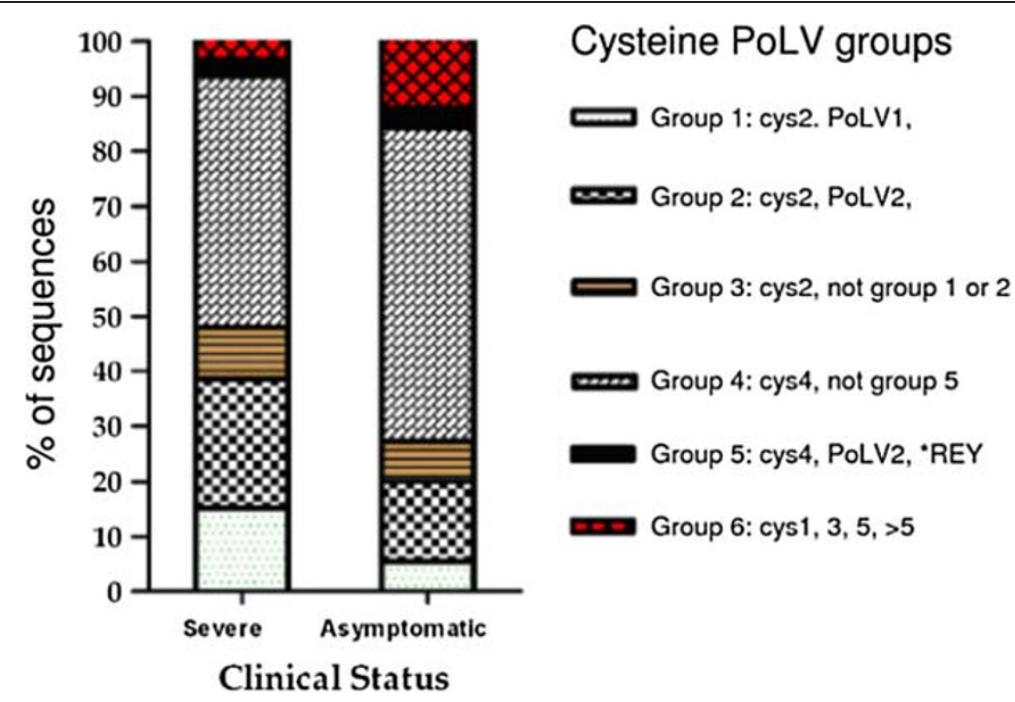

Figure 2 Distribution of DBL-1a sequences into cys/PoLV groups by clinical status. SM DBL-1a sequences had more than $50 \%$ cys2 sequence tags (1-3 groups) compared to $27 \%$ in AM isolates.

to be immense and unrestricted. However, a minimal overlap among var genes was found in different isolates. A similar finding has been reported by Barry et al. [41] for the cumulative DBL-1 $\alpha$ sequences from genomic DNA in the Amele, PNG, and for the global population, where in more than 1,000 sequences from 59 isolates plus the entire 3D7 var repertoire the saturation point of the var gene repertoires could not be reached.

\section{Phylogenetic analysis}

To study the sequence diversity between the SM and AM groups, a phylogenetic network was constructed using the three most dominant DBL-1 $\alpha$ variants expressed from each SM or AM isolate. The analysed sequences clustered in two distinct groups. The majority of the DBL- $1 \alpha$ isolates from severe malaria clustered together and belonged to var group $\mathrm{A}$ and B/A. AM isolates formed another cluster mainly consisting of $\operatorname{var} \mathrm{B}$, $\mathrm{B} / \mathrm{C}$ or $\mathrm{C}$ (Figure 5 ). To study further relationships between sequences, nine DBL-1 $\alpha$ sequences from the 3D7 genome were incorporated, three from each group $\mathrm{A}, \mathrm{B}$ and $\mathrm{C}$, in the construction of the phylogenetic tree. Among the sequences included was the group A var PF11_0008 which has been shown to be highly transcribed in the NF54 isolate [42] and group B var PF10_0406 which has been detected previously as a major transcript in 3D7B2 and 3D7B1 samples [43]. The DBL- $1 \alpha$ sequences analysed were found to cluster into two distinct clades. The majority of SM isolates and the 3D7 DBL-1 $\alpha$ sequences clustering together belonged to

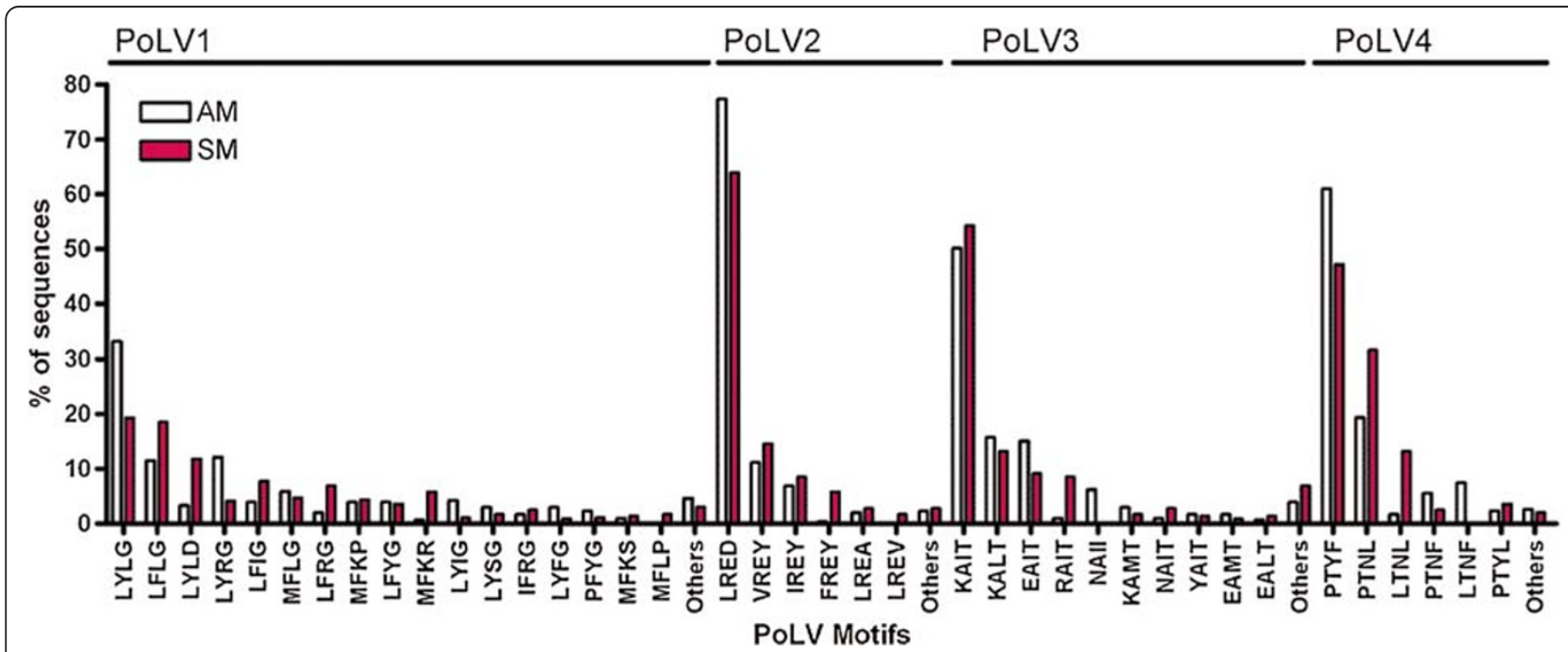

Figure 3 Distribution of PoLVmotifs within clinical isolates SM (red bars) and in AM (white bars). 


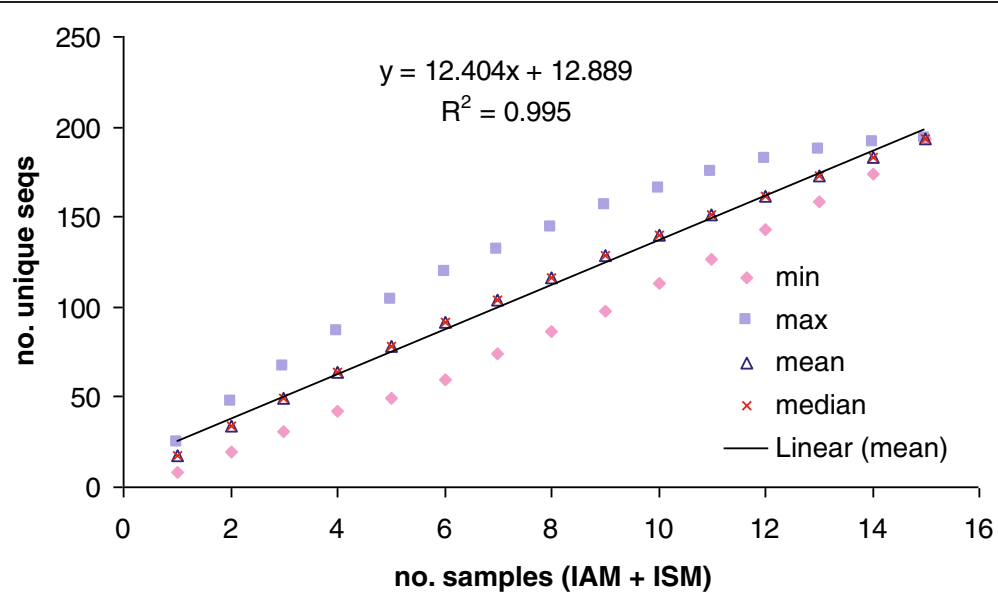

Figure 4 Cumulative diversity curves for DBL-1a sequences from Ifakara. The cumulative curve for DBL-1a was determined by simulation the number of unique sequences as a function of the number of patient samples. For each number of patient samples the statistics value was obtained from simulations of all possible sample combinations.

var group A. AM isolates and the other remaining 3D7 DBL-1 $\alpha$ sequences formed another cluster mainly belonging to var group $\mathrm{B}, \mathrm{B} / \mathrm{C}$ or $\mathrm{C}$ (Figure 6).

These findings again support the hypothesis that $\mathrm{SM}$ is caused by a restricted subset of var genes that belong to var group $\mathrm{A}$ or B/A whilst non severe malaria is attributed to the presence of another var gene group. Similarly, the phylogenetic approach of Kyriacou et al. [21] using DBL- $1 \alpha$ sequence tags from Mali identified var transcripts from group $\mathrm{A}$ and $\mathrm{B} / \mathrm{A}$ genes to be more frequent among parasites isolated from children with cerebral malaria than from patients with hyper-parasitaemia.

A multiple-sequence alignment of three dominant upsA sequences from clinical isolates together with upsA sequences from the 3D7 genome showed the existence of short islands of homology, conserved in all isolates suggesting that they might be structurally important. Phylogenetic analysis of the three dominant upsA sequences from clinical isolates and the 3D7 upsA sequences, showed an even distribution among clinical isolates (Figure 7). Two different methods for phylogenetic tree construction were used (MEGA 4.0 and SplitsTree 4.7) and both methods yielded similar tree topologies.

\section{Discussion}

Studies on var gene diversity are important in understanding malaria pathogenesis and in the design of disease interventions such as a vaccine or chemotherapies. In the present study, we examined var gene expression from clinical isolates of children with severe malaria and asymptomatic infections from Tanzania. In each isolate dominant expression of one particular var gene was found, together with less abundant variant transcripts and unique sequences. However, the dominant sequences differed between isolates. This suggests that each parasite contains its own set of var gene variants. This has the consequences that exposure to multiple infections and hence var gene products do not necessarily confer immunity to future malaria infections $[46,47]$.

By analysing the expressed var gene repertoires in severe malaria cases versus asymptomatic controls, we showed that the diversity within the var gene family is enormous with a minimal degree of overlaps between isolates. Kyriacou et al. [21] have found a minimal overlap in var gene repertoires after analysing the expressed sequence tags from Malian children with malaria infections. A recent study on molecular epidemiology of var genes in Africa has also shown a minimal overlap in var repertoires among parasite genomes [48]. In contrast, Albrecht et al. [49] reported a large overlap of the var gene repertoire in Western Amazon isolates. var repertoires of natural parasite populations found within specific geographical regions showed a degree of overlapping, suggesting the circulation of a similar var gene repertoire. This has important implications for the acquisition of long-term immunity by the exposed individuals [47].

The diversity of var genes within a natural $P$. falciparum population in a particular geographical region is difficult to define, and to assess whether the diversity is constant due to functional constrain on this molecule, fluctuating or constantly turning over, and how fast the turnover rate of the PfEMP1 repertoires could be. Changes in the var repertoire are believed to be due to high allelic and ectopic recombination rates of var genes in field isolates $[37,50,51]$ which are influenced by transmission intensity. The diversity of the PfEMP1 repertoire of parasites in a given geographical area is a key factor in the development of clinical immunity. The vast antigenic diversity and complexity of var gene repertoires in parasite populations may explain why individuals are 


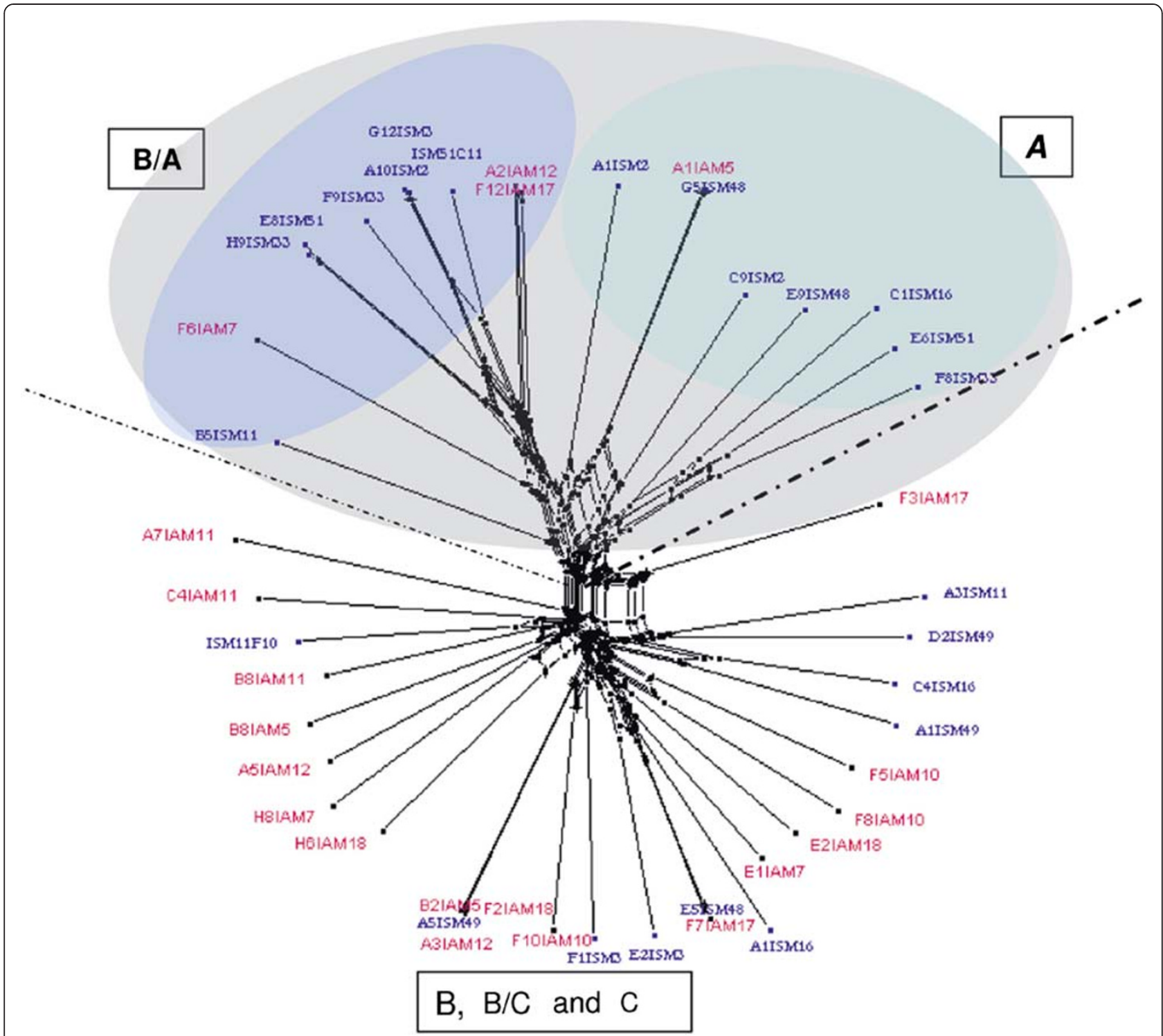

Figure 5 Phylogenetic network showing the comparison of 3 dominant DBL-1a sequence tags transcribed from clinical isolates, generated using Neighbour-Net [44]. Sequences transcribed by isolates with severe malaria (ISM, blue) and asymptomatic malaria (IAM, red) are compared. The sequences fall into two major clades separated with dotted lines, the upper cluster formed 2 subgroups of sequences isolated from severe patients, one with group $A$ and the remaining var group B/A homology to 3D7. The majority of sequences from asymptomatic patient isolates clustered together and were homologous to group $B, B / C$ and $C$ of the $3 D 7$ genome.

repeatedly susceptible to $P$. falciparum infections and never develop sterilizing immunity. The antigenic variation and high switching rate of var gene expression are effective mechanisms adopted by $P$. falciparum to evade the host's immune system, for survival, and effective transmissions.

In this study, several sequences were observed more frequently than others within individual patients. This is consistent with previous studies of var gene diversity $[21,22,46,50,51]$. The variability of the DBL- $1 \alpha$ and upstream sequences within an isolate was found to be similar to different isolates in both the groups (SM \& AM).
AM isolates were more diverse as reflected by the presence of more singletons suggesting that var genes associated with asymptomatic infection have an enormous repertoire which could explain the difficulty of acquiring immunity to mild or asymptomatic malaria.

Isolates from children with severe malaria were predominantly found to transcribe var genes with a DBL- $1 \alpha$ domain that had a reduced number of cysteine residues which is the characteristic of var group A. Similar results have been reported previously from other research groups in Kenya, Mali, and Brazil [20-22]. This supports the notion that severe malaria might be caused 


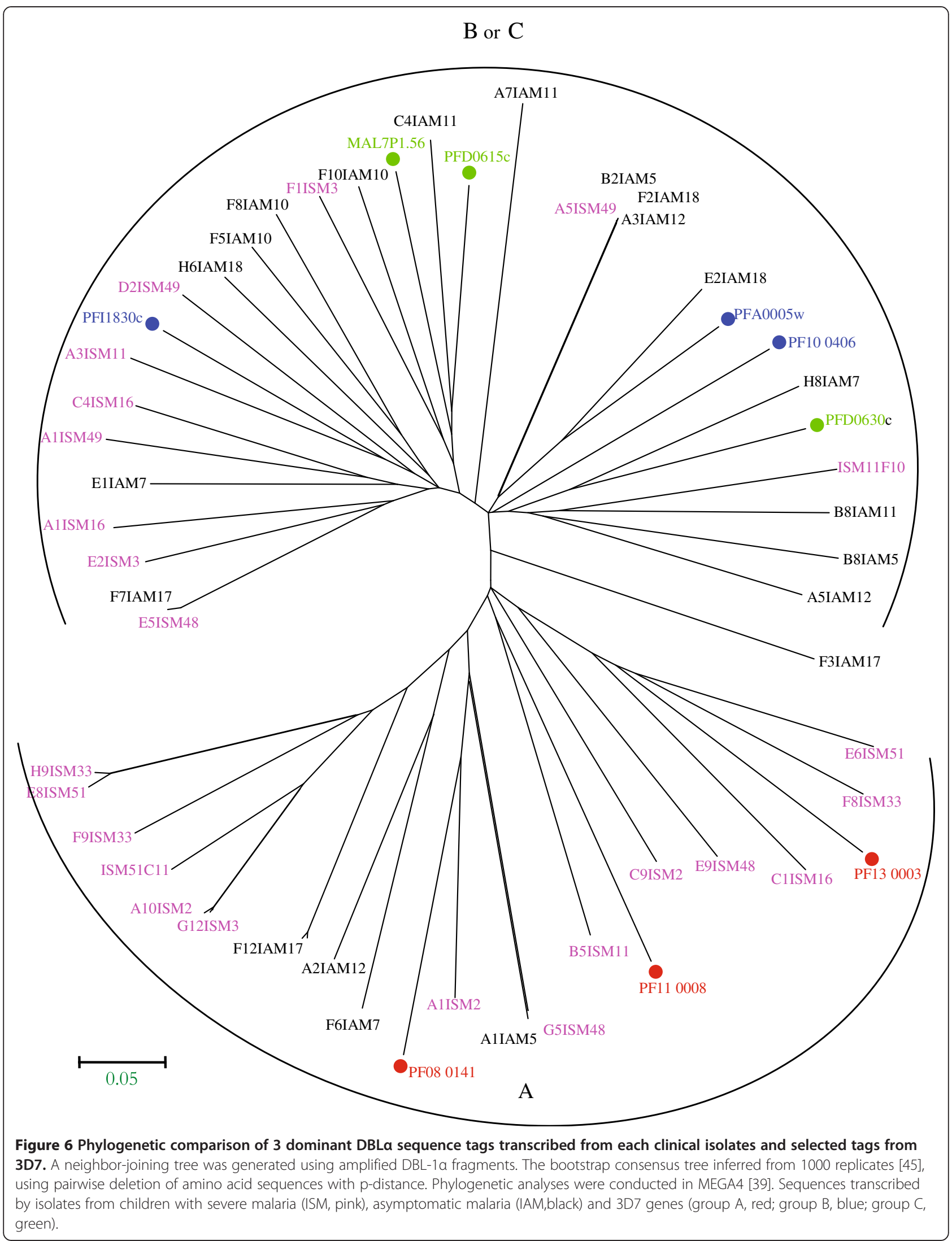




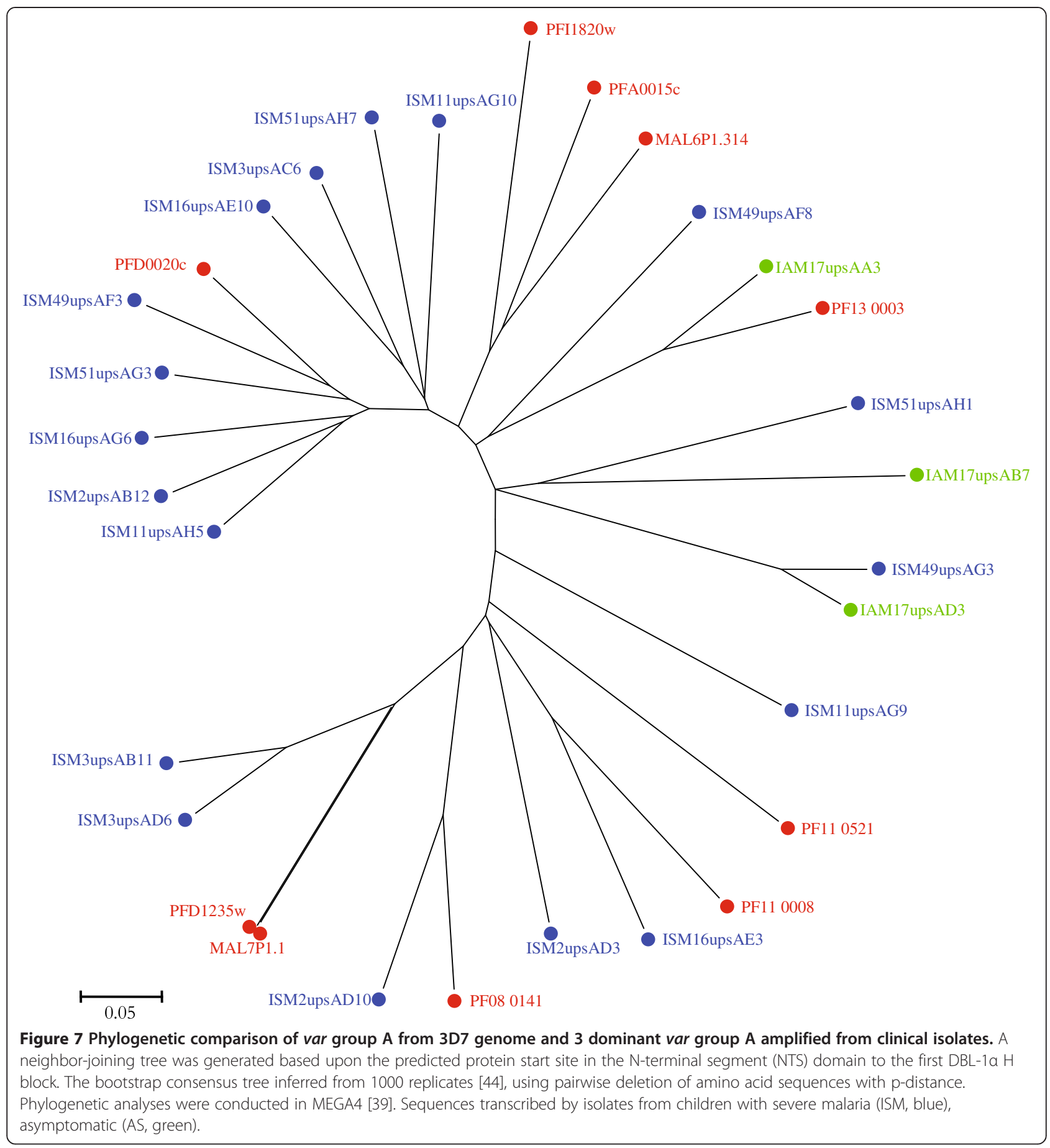

by a restricted subset of var genes and confirms that group A var genes are involved in severe disease similarly as we had shown in a previous study that group A var genes were up regulated in children with cerebral malaria [25]. However, most studies on var gene diversity have been relying on the use of DBL- $1 \alpha$ fragments [50]. DBL- $1 \alpha$ primers amplify only a small fragment of the var gene that is more conserved than other var domains and that is found in most of PfEMP1 proteins.
Due to the complex nature of var genes, only recently complete var genes could be cloned routinely [52] and could provide in future additional information on understanding var gene transcription and its association to disease phenotype.

Cluster analysis revealed several 'unique sequences' of var genes which were transcribed only in isolates from patients with severe malaria. Expression of these 'unique sequences' in a patient who lacks a pre-existing antibody 
response against this variant might trigger the development of severe malaria. Once exposed to these potentially virulent var genes individuals living in endemic areas may acquire immunity to severe malaria. In areas of high endemicity this might happen early in life after only a few clinical episodes. The distribution of PoLV motifs showed 8 motifs which were highly associated with severe disease. Based on the MOTIFF algorithm, Normark et al. [53] identified 15 DBL-1 $\alpha$ degenerate sequence motifs pertinent to severe disease and three motifs associated with the high rosetting phenotype after analysing 93 patients with well-characterized disease. Once again pointing in the direction that disease phenotypes are correlated with the expression of certain PfEMP1 variants and motifs. This is highly relevant information for vaccine development and understanding disease pathogenesis.

The distribution of PF11_0008, a group A var gene, which previously has been identified in the 3D7 genome and the isogenic isolate NF54 [42], was found in three SM isolates (ISM11, ISM33, ISM48) and in one AM sample (IAM17), although in low frequencies. This, and the observation that PFD0020c also has been more frequently found in SM cases suggests that the var genes of laboratory strains are shared among the field isolates. The recent report by Claessens et al. [54] showing that up-regulation of the group A var gene 3D7_PFD0020c is associated with adhesion to human brain endothelial cells further supports this notion.

\section{Conclusion}

The var family is highly diverse in natural $P$. falciparum populations, but this diversity was more restricted in severe malaria than in asymptomatic isolates, and this finding suggests a fundamental role played by different subsets of var transcripts in disease syndromes. Further analysis of this molecule is required from many geographical regions with well-defined malaria infections. Such an approach might provide the basis for an innovative vaccine or chemotherapy intervention. To gain better understanding of var gene diversity and function future work should be focused on analysis of full-length sequences and the analysis of protein function and immunological responses.

\section{Competing interests}

The authors declare no competing interests.

\section{Authors' contributions}

JM, SR, MR, HPB conceived and designed the study, JM and SR conducted the laboratory analysis, WQ and JM analysed the data. JM and HPB wrote the manuscript with contributions from all other authors. All authors read and approved the final manuscript.

\section{Acknowledgements}

We would like to thank the parents and guardians who participated in this study. We are grateful to the staff of St Francis Referral Hospital for their continuing support of the study and care of the patients. We thank Kefas
Mugittu, Tarsis Pius, Boniface Jullu, and Krischan Bäumli for their laboratory support. We are indebted to Ingrid Felger for critically reviewing the manuscript. We are very grateful to Dorothee Foernzler and Michael Ott at Hoffmann La Roche Pharma AG for their support in sequencing. This study was supported by the Optimus Foundation and the Swiss National Science Foundation (3100 A0 - 104043/1).

\section{Author details}

${ }^{1}$ Ifakara Health Institute, Ifakara, Tanzania. ${ }^{2}$ Swiss Tropical and Public Health Institute, Socinstrasse 57 Postfach, Basel 4002, Switzerland. ${ }^{3}$ University of Basel, Switzerland. ${ }^{4}$ present address: Genome centre, Zürich, Switzerland.

Received: 15 February 2012 Accepted: 2 July 2012

Published: 16 July 2012

\section{References}

1. WHO: World malaria report: 2011. Geneva: World Health Organization; 2011.

2. Gupta S, Snow RW, Donnelly CA, Marsh K, Newbold C: Immunity to non cerebral severe malaria is acquired after one or two infections. Nat Med 1999, 5:340-343.

3. Bull PC, Marsh K: The role of antibodies to Plasmodium falciparuminfected-erythrocyte surface antigens in naturally acquired immunity to malaria. Trends Microbiol 2002, 10:55-58.

4. Kyes $S$, Horrocks P, Newbold C: Antigenic variation at the infected red cell surface in malaria. Annu Rev Microbiol 2001, 55:673-707.

5. Gardner MJ, Hall N, Fung E, White O, Berriman M, Hyman RW, Carlton JM, Pain A, Nelson KE, Bowman S, Paulsen IT, James K, Eisen JA, Rutherford K, Salzberg SL, Craig A, Kyes S, Chan MS, Nene V, Shallom SJ, Suh B, Peterson J, Angiuoli S, Pertea M, Allen J, Selengut J, Haft D, Mather MW, Vaidya AB, Martin DM, Fairlamb AH, Fraunholz MJ, Roos DS, Ralph SA, McFadden Gl, Cummings LM, Subramanian GM, Mungall C, Venter JC, Carucci DJ, Hoffman SL, Newbold C, Davis RW, Fraser CM, Barrell B: Genome sequence of the human malaria parasite Plasmodium falciparum. Nature 2002, 419:498-511.

6. Baruch DI, Pasloske BL, Singh HB, Bi X, Ma XC, Feldman M, Taraschi TF, Howard RJ: Cloning the $P$. falciparum gene encoding PfEMP1, a malarial variant antigen and adherence receptor on the surface of parasitized human erythrocytes. Cell 1995, 82:77-87.

7. Smith JD, Chitnis CE, Craig AG, Roberts DJ, Hudson-Taylor DE, Peterson DS, Pinches R, Newbold Cl, Miller LH: Switches in expression of Plasmodium falciparum var genes correlate with changes in antigenic and cytoadherent phenotypes of infected erythrocytes. Cell 1995, 82:101-110.

8. Su XZ, Heatwole VM, Wertheimer SP, Guinet F, Herrfeldt JA, Peterson DS, Ravetch JA, Wellems TE: The large diverse gene family var encodes proteins involved in cytoadherence and antigenic variation of Plasmodium falciparum-infected erythrocytes. Cell 1995, 82:89-100.

9. Chen Q, Barragan A, Fernandez V, Sundström A, Schlichtherle M, Sahlén A, Carlson J, Datta S, Wahlgren M: Identification of Plasmodium falciparum erythrocyte membrane protein 1 (PfEMP1) as the rosetting ligand of the malaria parasite P. falciparum. J Exp Med 1998, 187:15-23.

10. Rowe JA, Moulds JM, Newbold Cl, Miller LH: P. falciparum rosetting mediated by a parasite-variant erythrocyte membrane protein and complement-receptor 1. Nature 1997, 388:292-295.

11. Vogt AM, Barragan A, Chen Q, Kironde F, Spillmann D, Wahlgren M: Heparan sulfate on endothelial cells mediates the binding of Plasmodium falciparum-infected erythrocytes via the DBL1 alpha domain of PfEMP1. Blood 2003, 101:2405-2411.

12. Mayor A, Bir N, Sawhney R, Singh S, Pattnaik P, Singh SK, Sharma A, Chitnis CE: Receptor-binding residues lie in central regions of Duffy-binding-like domains involved in red cell invasion and cytoadherence by malaria parasites. Blood 2005, 105:2557-2563.

13. Fairhurst RM, Baruch DI, Brittain NJ, Ostera GR, Wallach JS, Hoang HL, Hayton K, Guindo A, Makobongo MO, Schwartz OM, Tounkara A, Doumbo OK, Diallo DA, Fujioka H, Ho M, Wellems TE: Abnormal display of PfEMP-1 on erythrocytes carrying haemoglobin $C$ may protect against malaria. Nature 2005, 435:1117-1121.

14. Rowe JA, Rogerson SJ, Raza A, Moulds JM, Kazatchkine MD, Marsh K, Newbold Cl, Atkinson JP, Miller LH: Mapping of the region of complement receptor (CR) 1 required for Plasmodium falciparum rosetting and demonstration of the importance of CR1 in rosetting in field isolates. J Immunol 2000, 165:6341-6346. 
15. Lavstsen T, Salanti A, Jensen AT, Arnot DE, Theander TG: Sub-grouping of Plasmodium falciparum 3D7 var genes based on sequence analysis of coding and non-coding regions. Malar J 2003, 2:27.

16. Bull PC, Kortok M, Kai O, Ndungu F, Ross A, Lowe BS, Newbold Cl, Marsh K Plasmodium falciparum-infected erythrocytes: agglutination by diverse Kenyan plasma is associated with severe disease and young host age. $\mathrm{J}$ Infect Dis 2000, 182:252-259.

17. Nielsen MA, Staalsoe T, Kurtzhals JA, Goka BQ, Dodoo D, Alifrangis M, Theander TG, Akanmori BD, Hviid L: Plasmodium falciparum variant surface antigen expression varies between isolates causing severe and non severe malaria and is modified by acquired immunity. J Immunol 2002, 168:3444-3450.

18. Gamain B, Smith JD, Viebig NK, Gysin Scherf A: Pregnancy-associated malaria: parasite binding, natural immunity and vaccine development. Int J Parasitol 2007, 37:273-283

19. Salanti A, Dahlbäck M, Turner L, Nielsen MA, Barfod L, Magistrado P, Jensen AT, Lavstsen T, Ofori MF, Marsh K, Hviid L, Theander TG: Evidence for the involvement of VAR2 CSA in pregnancy-associated malaria. J Exp Med 2004, 200:1197-1203.

20. Bull PC, Berriman M, Kyes S, Quail MA, Hall N, Kortok MM, Marsh K, Newbold Cl: Plasmodium falciparum variant surface antigen expression patterns during malaria. PLoS Pathog 2005, 1:e26.

21. Kyriacou HM, Stone GN, Challis RJ, Raza A, Lyke KE, Thera MA, Koné AK Doumbo OK, Plowe CV, Rowe JA: Differential var gene transcription in Plasmodium falciparum isolates from patients with cerebral malaria compared to hyper-parasitaemia. Mol Biochem Parasitol 2006, 150:211-218.

22. Kirchgatter $K$, del Portillo HA: Association of severe noncerebral Plasmodium falciparum malaria in Brazil with expressed PfEMP1 DBL1 alpha sequences lacking cysteine residues. Mol Med 2002, 8:16-23.

23. Kaestli M, Cortes A, Lagog M, Ott M, Beck HP: Longitudinal assessment of Plasmodium falciparum var gene transcription in naturally infected asymptomatic children in Papua New Guinea. J Infect Dis 2004, 189:1942-1951.

24. Ariey F, Hommel D, Le Scanf C, Duchemin JB, Peneau C, Hulin A, Sarthou JL, Reynes JM, Fandeur T, Mercereau-Puijalon O: Association of severe malaria with a specific Plasmodium falciparum genotype in French Guiana. J Infect Dis 2001, 184:237-241.

25. Rottmann M, Lavstsen T, Mugasa JP, Kaestli M, Jensen AT, Müller D, Theander T, Beck HP: Differential expression of var gene groups is associated with morbidity caused by Plasmodium falciparum infection in Tanzanian children. Infect Immun 2006, 74:3904-3911.

26. Montgomery J, Mphande FA, Berriman M, Pain A, Rogerson SJ, Taylor TE, Molyneux ME, Craig A: Differential var gene expression in the organs of patients dying of falciparum malaria. Mol Microbiol 2007, 65:959-967.

27. Falk N, Kaestli M, Qi W, Ott M, Baea K, Cortés A, Beck HP: Analysis of Plasmodium falciparum var genes expressed in children from Papua New Guinea. J Infect Dis 2009, 200:347-356.

28. Bustin SA: Absolute quantification of mRNA using real-time reverse transcription polymerase chain reaction assays. J Mol Endocrinol 2000, 25:169-193.

29. WHO: Severe falciparum malaria. Trans R Soc Trop Med Hyg 2000, 94(Suppl. 1):S1-S90.

30. Molyneux ME, Taylor TE, Wirima JJ, Borgstein A: Clinical features and prognostic indicators in paediatric cerebral malaria: a study of 131 comatose Malawian children. Q J Med 1989, 71:441-459.

31. Falk N, Maire N, Sama W, Owusu-Agyei S, Smith T, Beck HP, Felger I: Comparison of PCR-RFLP and Genescan-based genotyping for analyzing infection dynamics of Plasmodium falciparum. Am J Trop Med Hyg 2006, 74:944-950.

32. Kraemer SM, Gupta L, Smith JD: New tools to identify var sequence tags and clone full-length genes using type-specific primers to Duffy bindinglike domains. Mol Biochem Parasitol 2003, 129:91-102.

33. Aurrecoechea C, Brestelli J, Brunk BP, Dommer J, Fischer S, Gajria B, Gao X Gingle A, Grant G, Harb OS, Heiges M, Innamorato F, lodice J, Kissinger JC, Kraemer E, Li W, Miller JA, Nayak V, Pennington C, Pinney DF, Roos DS, Ross C, Stoeckert CJ Jr, Treatman C, Wang H: PlasmoDB: a functional genomic database formalaria parasites. Nucleic Acids Res 2009,

37(Database issue):D539-D543.

34. Wernersson R, Pedersen AG: RevTrans: multiple alignment of coding DNA from aligned amino acid sequences. Nucleic Acids Res 2003, 31:537-539.
35. Edgar RC: MUSCLE: multiple sequence alignment with high accuracy and high throughput. Nucleic Acids Res 2004, 32:1792-1797.

36. Altschul SF, Gish W, Miller W, Myers EW, Lipman DJ: Basic local alignment search tool. J Mol Biol 1990, 215:403-410.

37. Freitas-Junior LH, Bottius E, Pirrit LA, Deitsch KW, Scheidig C, Guinet F, Nehrbass U, Wellems TE, Scherf A: Frequent ectopic recombination of virulence factor genes in telomeric chromosome clusters of $P$. falciparum. Nature 2000, 407:1018-1022.

38. Russo CA, Takezaki N, Nei M: Efficiencies of different genes and different tree-building methods in recovering a known vertebrate phylogeny. $\mathrm{Mol}$ Biol Evol 1996, 13:525-536.

39. Tamura K, Dudley J, Nei M, Kumar S: MEGA4: molecular evolutionary genetics analysis (MEGA) software version 4.0. Mol Biol Evol 2007, 24:1596-1599.

40. Huson DH, Bryant D: Application of phylogenetic networks in evolutionary studies. Mol Biol Evol 2006, 23:254-267.

41. Barry AE, Leliwa-Sytek A, Tavul L, Imrie H, Migot-Nabias F, Brown SM, McVean GA, Day KP: Population genomics of the immune evasion (var) genes of Plasmodium falciparum. PLoS Pathog 2007, 3:e34.

42. Lavstsen T, Magistrado P, Hermsen CC, Salanti A, Jensen AT, Sauerwein R, Hviid L, Theander TG, Staalsoe T: Expression of Plasmodium falciparum erythrocyte membrane protein 1 in experimentally infected humans. Malar J 2005, 4:21

43. Peters J, Fowler E, Gatton M, Chen N, Saul A, Cheng Q: High diversity and rapid changeover of expressed var genes during the acute phase of Plasmodium falciparum infections in human volunteers. Proc Natl Acad Sci USA 2002, 99:10689-10694

44. Bryant D, Moulton V: Neighbor-net: an agglomerative method for the construction of phylogenetic networks. Mol Biol Evol 2004, 21:255-265.

45. Felsenstein J: Confidence limits on phylogenys: an approach using the bootstrap. Evolution 1985, 39:783-791.

46. Fowler EV, Peters JM, Gatton ML, Chen N, Cheng Q: Genetic diversity of the DBL alpha region in Plasmodium falciparum var genes among AsiaPacific isolates. Mol Biochem Parasitol 2002, 120:117-126.

47. Trimnell AR, Kraemer SM, Mukherjee S, Phippard DJ, Janes JH, Flamoe E, Su XZ, Awadalla P, Smith JD: Global genetic diversity and evolution of var genes associated with placental and severe childhood malaria. Mol Biochem Parasitol 2006, 148:169-180.

48. Chen DS, Barry AE, Leliwa-Sytek A, Smith TA, Peterson I, Brown SM, MigotNabias F, Deloron P, Kortok MM, Marsh K, Daily JP, Ndiaye D, Sarr O, Mboup S, Day KP: A molecular epidemiological study of var gene diversity to characterize the reservoir of Plasmodium falciparum in humans in Africa. PLoS One 2011, 6:e16629.

49. Albrecht L, Castiñeiras C, Carvalho BO, Ladeia-Andrade S, Santos da Silva N, Hoffmann EH, dallamartha RC, Costa FT, Wunderlich G: The South American Plasmodium falciparum var gene repertoire is limited, highly shared and possibly lacks several antigenic types. Gene 2010, 453:37-44.

50. Conway DJ, Roper C, Oduola AM, Arnot DE, Kremsner PG, Grobusch MP Curtis CF, Greenwood BM: High recombination rate in natural populations of Plasmodium falciparum. Proc Natl Acad Sci U S A 1999, 96:4506-4511.

51. Taylor HM, Kyes SA, Newbold Cl: Var gene diversity in Plasmodium falciparum is generatedby frequent recombination events. Mol Biochem Parasitol 2000, 110:391-397.

52. Gaida A, Becker MM, Schmid CD, Bühlmann T, Louis EJ, Beck HP: Cloning of the repertoire of individual Plasmodium falciparum var genes using transformation associated recombination (TAR). PLOS One 2011, 6:e17782.

53. Normark J, Nilsson D, Ribacke U, Winter G, Moll K, Wheelock CE, Bayarugaba J, Kironde F, Egwang TG, Chen Q, Andersson B, Wahlgren M: PfEMP1-DBL1 alpha amino acid motifs in severe disease states of Plasmodium falciparum malaria. Proc Natl Acad Sci U S A 2007, 104:15835-15840.

54. Claessens A, Adams Y, Ghumra A, Lindergard G, Buchan CC, Andisi C, Bull PC, Mok S, Gupta AP, Wang CW, Turner L, Arman M, Raza A, Bozdech Z, Rowe JA: A subset of group A-like var genes encodes the malaria parasite ligands for binding to human brain endothelial cells. Proc Natl Acad Sci USA 2012, 109:E1772-E1781.

\section{doi:10.1186/1475-2875-11-230}

Cite this article as: Mugasa et al:: Genetic diversity of expressed Plasmodium falciparum var genes from Tanzanian children with severe malaria. Malaria Journal 2012 11:230. 